\title{
Green design, low carbon environmental protection-the only way for
}

\section{sustainable development design}

\author{
Na Wang ${ }^{1, a^{*}}$ Changbai $\mathrm{Yu}^{2,3, \mathrm{~b}}$ Jiwei $\mathrm{Wu}^{4, \mathrm{c}}$ \\ (1. Wuhan Institute of Design and Sciences 2. Institute of Sinopec Oilfield Equipment Corporation \\ 3.SINOPEC Key Laboratory of Petroleum Equipment 4. Yangtze University) \\ aemail690508622@qq.com, bemail 19473222@qq.com, cemail 372329469@qq.com
}

Keywords: Green design; Low carbon environmental protection; Sustainable development; Industrial Design

\begin{abstract}
Industrial design has accelerated the consumption of resources and energy, and also caused the deterioration of the natural environment and ecological balance.Based on green design ,basic connotation and far-reaching significance of low carbon environmental protection,this paper analyzes the relationship between green design, low carbon environmental protection and sustainable development .It is concluded that the design concept of current sustainable development is green design and low carbon environmental protection, making the design of human nature and harmony to be truly reflected, and putting forward higher requirements for social responsibility and professional ethics of the design humans. It has a very important practical significance.
\end{abstract}

\section{Introduction}

In the long history of human beings design, it created the modern life style and environment. Meanwhile, accelerated resource and energy consumption and caused damage to earth eco-balance. Hence, industrial design began based on green design and low carbon environmental protection ${ }^{[1-3]}$.

Green design, low carbon environmental protection focus on the ecological balance between man and nature, as far as possible to reduce the damage to the living environment of the strategic height to architecture design strategy. It promotes the development of economy and culture with the development of green design and low carbon environment. Green design and low carbon environmental protection shows the strategy of inter coordination between environmental protection and economic and sustainable development. Environmental protection, green design development and low carbon environmental protection have been the only way for every country over the world to develop industrial design, and it also have been the inevitable trend for industrial design community development ${ }^{[4-7]}$.

\section{Introduction of green design and low carbon environmental protection}

The basic meaning of green design. Victor Babanak, An American design theoretician, firstly introduced the green design. In 1960s he introduced limited resource theory in design for a real world, emphasizing serious consideration of use of limited earth resource and environmental protection when designing. This publication aroused a controversy while was commonly recognized after energy crisis. A number of countries accelerated green design and manufacture using administrative means ${ }^{[8-11]}$. And more than 20 countries have started environmental certification to products.

Green design (namely eco-design, environmental design, life circle design or environmental awareness design) is a design which focuses on product's environmental property(detachability, 
recyclability, maintainability and repeatable utilization) in the whole life circle. Meanwhile, it ensures the function, life and quality while fulfilling the demand of environmental goals. Green design also means considering the repeatable utilization or safe landfill after life end when designing, which restrains environmental pollution. It is named ecological design or design for environment as well. Although it has different names, they mean the same. The basic idea is to consider environmental factors and measures for pollution prevention when designing. It considers environmental performance as design objectives and starting point in order to minimize the impact of the product on the environment. The concept, starting from industrial design, essentially means making product come from nature, back to nature and go close to nature in essence. At present, it has become a developing trend of the design industry. Green design environmental protection aims at saving resource and environmental protection, emphasizing protecting natural ecology, making the full use of resource, people oriented and being environmentally friendly.

Current situation of green design and low carbon environmental protection. In 1987 WEDC firstly illustrated the concept of sustainable development in Our Common Future that has been well recognized in international society. With this background, the central government put forward the scientific outlook on development of insisting people oriented, carrying out comprehensive, coordinated and sustainable development. It is true and timely. Green product, green design and low carbon environmental protection, as a result of people-nature coordinated development and sustainable development requirement for saving resource, effective use of energy and environmental protection, have been the new trend of this time.

With the development of social economy, the idea of sustainable development has been deeply rooted in the hearts of people. As the current style of sustainable development, green design and low carbon environmental protection are urgent.

Green design and low carbon environmental protection. The eco-balance, which is popular now, is a method of assessment. It mainly considers energy consumption, recycle, material utilization, pollution and waste. It contains material selection and management of green design, product disassembly design and repeatable utilization design of the product. On the one hand, the material with injurious ingredient cannot be mixed with that without. On the other hand, for product life cycle, the useful part should be fully recycled and the useless part should be handled with some technique to minimize its negative effect to environment. The recovery possibility, recovery value and recovery technique should be comprehensively considered.

The designer should design the product to be easily detached, maintained and recycled after life ending. Besides, the cost analysis and design database for green design should be taken into consideration.

Development trend of green design and low carbon environmental protection. 1. Humanized design trend. For the current situation of green design and low carbon environmental protection, the space and necessity of the development can be seen. Especially humanization should be incorporated into green design and low carbon environmental protection, which is the requirement of the new industry design time.

2. Ecological design trends. The base of green design and low carbon environmental protection is human beings' benefit. It pursues to efficiently use nature, back to nature, reuse, reduce pollution and protect the environment.

3. Rationalization design trend. Green design and low carbon environmental protection should comprehensively consider the condition of light, sound and air quality and related device. 
4. Continuity design trend. Health, benefit, low energy consuming and low pollution green design, low carbon environmental protection concept design cover a new concept of eco-environment and sustainable development.

Far-reaching significance of extensively spreading green design and low carbon environmental protection. 1. People life style has been changed. High energy consuming, high material consuming and massive waste from them greatly damaged people living environment. Meanwhile, the life styles is not sustainable. Green design and low carbon environmental protection idea and its product encourage people to pursue not only material but also ecological civilization, which is green life styles.

2. Technological progress and innovation have been accelerated. In the past, the economic benefit has been more assessed than environmental and ecological effects when evaluating whether a technology is advanced or not. Green design and low carbon environmental protection require to consider society, economy and ecological benefit, and to strike a coordination and unification among them. It puts forward a high demand to product design, accelerating technological progress and innovation and meeting the demand of economic and sustainable development of human society.

3. It meets the demand of international trade. In international trade, it has been an international standard that commodity that does not meet international standard is forbidden to be imported. Utilizing green design and low carbon environmental protection idea produces the product that better meet international standard, better introduce our national product to extensive international market and improve our competitiveness.

4. It has an important effect on the area sustainable development. China's 21 Century Agenda prior field consist cleaner production and environmental protection industry. In the implementation of it, green design and low carbon environmental protection can make a big difference. With designing energy saving and environmentally friendly technological product, it makes its own contribution to the sustainable development.

5. It is an important measure in the era of knowledge economy. Green products are characterized as energy saving, no hazardous chemicals, reasonable packing and easily detachable. Hence, the green industry, with the directory idea of developing green design and low carbon environmental protection, means much in environmental protection. In twenty-first Century with the coming knowledge economy, green design, low carbon environmental protection, green product and green industry is important for companies to pursue. It is a critical part to coordinate our population, resource, environment and development.

Extensive spreading green design and low carbon environmental protection and its main reflect. 1 . Enhance the publicity of green environmental protection; improve the awareness of green design and low carbon environmental protection in all sociey. Establish a sound legal and compound system for green environmental protection and beneficial economic development, forming a safe, stable and efficient green environmental system.

2. Continue to expand green products, industry and market to improve the whole society green design, low carbon environmental protection consciousness. Build a green environmental protective economic system oriented with green product whose principal part is green cars, food and modern Chinese medicine.

3. Enhance green environment construction for urban and suburban people, and Form a harmonious society based on the main characteristics of green resources, green products, green enterprises, green environment.

4. Enhance green culture construction and improve people green culture quality. 


\section{Green design, low carbon environmental protection and sustainable development}

(I) the natural environment calls for the return of the green civilization, paying attention to the sustainable development design. In the design of a wide range of green design, low carbon environmental protection, in fact, it is only in a concept of the stage, the implementation is very difficult. Through the analysis the main contradiction factors of green design, low carbon environmental protection, to remind people of green design, low carbon environmental protection must face the actual situation and explore the practical implementation plan, so that the green design, low carbon environmental protection concept than slate into a strong way to design human healthy life.

(II) Actively promoting green design, low carbon environmental protection, to achieve sustainable design and development. "Green design, low carbon environmental protection" is fully reflected in the natural environment design. This paper calls for more designers to pay attention to our environment, to realize the green design, the low carbon environmental protection, and to include in the design of the concept of green.

(III) Designers who have green design and low carbon environmental protection follow the following ideas in their work. a. Harmonious principle. Promoting the harmonious and sustainable development of man and nature. Constructing the development mode of circular economy and building a resource-saving and harmonious society.

b. Development principle. To strengthen ecological construction and environmental protection, improve environmental quality, form a green ecological barrier and realize green design, low carbon environmental protection and sustainable development.

c. Rational principle. Adhere to the guide of scientific development concept, in accordance with the principle of highlight key, Accelerate the pace of development of the green industry in line with the requirements of circular economy, To restrict the development of forest cutting, grassland animal husbandry, traditional planting industry and high investment, high pollution enterprises, and realize sustainable development, as shown in Fig.1.

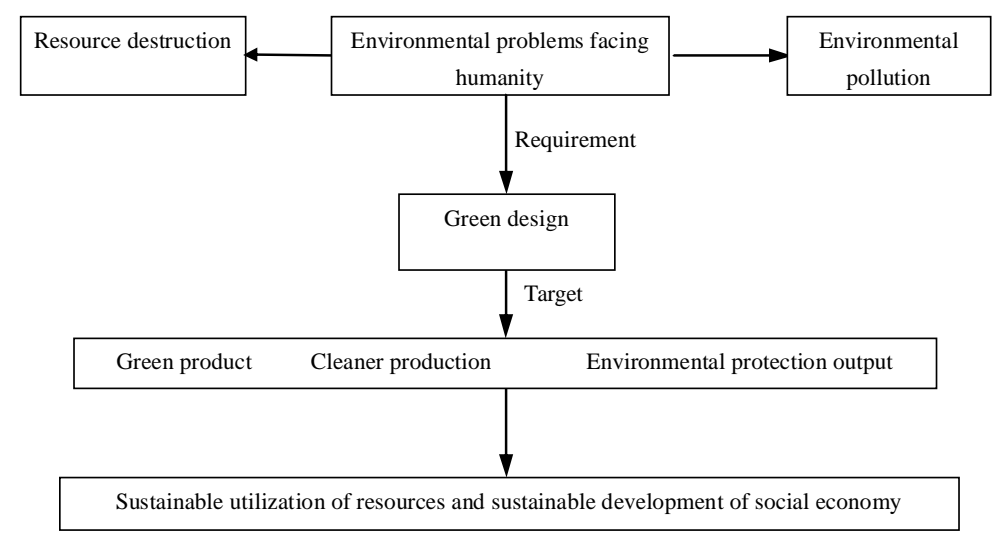

Fig.1 Key factors relationships of green design

"Green design, low carbon environmental protection attached to the use of renewable resources," resource regeneration design "is the highest voice and most enthusiastic of three" RE "(such as, Reduce , Reuse , Recycling ) design principles, progress is also the most obvious trend."

"Green design, low carbon and environmental protection are aimed to preserve natural resources, to prevent industrial pollution damaging to the ecological balance. Although it is still in its infancy, but has become a new trend of development." At the same time, it is also a contemporary human subject, which has basically achieved a global consensus. The recognition of this knowledge is based on the serious damage to the living environment of mankind. The development of society, the 
progress of science and technology, has brought a lot of convenience to people's life. In order to meet the material, on the one hand, humans continue to acquire resources in nature; on the other hand, human beings have kept producing waste and rubbish, resulting in the consequences of environmental pollution and ecological destruction, resource depletion, in the development process. Green design, low carbon and environmental protection from the rise of the United States in the United States in the 60 years of anti-consumer movement. In the 70 's, the similar criticism was in response to the call of multiple design. With the advent of the 21 st century, for our own survival and development, design boundary proposed the slogan of "green design, low carbon environmental protection", namely: theme concepts and methods based on resource conservation and environmental protection, protection of natural ecology, making full use of resources, green design, low carbon environmental trends are beginning to impact on the world, unstoppable.

The 1980s-1990s was the design of the diversification of the summer, in the exploration of the design style can be said to be "the Warlords" brilliant. And the designs of the "green" have become a conspicuous bright spot, and gradually form an irreversible trend. In the context of the natural environment of human existence, the protection of natural resources, save energy, maintain a good living environment, and create a green design to rebuild human healthy and harmonious home, has become a very pressing issue for the sustainable development of human society. And the green design, low carbon environmental protection for some exploration. For such a large subject system, it is a very important practical significance.

In the relationship between man and nature, regardless of the natural environment and the ability to bear and mindless emphasizing the development of GDP as a symbol, will lead to the conflict between human and nature, and thus cause the loss of human nature, the ultimate cause of adult inner conflict. All kinds of conflicts caused the moral crisis, social crisis, crisis of value, ecological crisis and spiritual crisis. But from the fundamental perspective, all disharmony phenomena are triggered by the disharmony relationship between people and people.

Along with the rapid development of modern science and technology, human beings have ignored the technology "progress" to the destruction of natural resources and the harm to human living environment. In the era of economic globalization, the world design globalization has become an inevitable trend. The green design, low carbon environmental protection are related to the human society today and the future, which makes the world design into a new realm.

\section{Conclusions}

Based on the current demand for green design, low carbon environmental protection, the design of human nature and harmony has been reflected. This is not only the attention paid to the industrial design status, but also the social responsibility of designers.

Green design, low carbon environmental protection in the design of sustainable development today, is not just a fashionable slogan, but closely related to the vital interests of each individual. It has a huge contribution to coming generations and society development for all human beings.

The emergence of green design, low carbon and environmental protection, is the result of the comprehensive effect of many factors and human sustainable development trend. It will also become one of the hot spots in the future design. In order to maintain the ecological balance and protect the environment, the design must take full account of the whole life cycle of the product, and also requires the designer to have a high degree of professional ethics, social responsibility and environmental protection awareness. 


\section{References}

[1] Renke He. Industrial design history (Revised Edition) [M]. Second edition. Beijing Institute of Technology press.2000.In Chinese

[2] Dingbang Yin. Introduction to design. Hunan science and Technology Press,.2000, August, 20-22. In Chinese

[3] Liangzhi Li. The history of world industrial design [M]. Beijing: China Light Industry Press.2001

[4]Robert Olsen, Ming zhe compiled. Sustainable future choice. 1994 fifth.

[5] Xiangqian Li, Ying Zeng, economic development model of green economy to twenty-first Century. Southwestern University of Finance and Economics press. In Chinese

[6] Xianyi Yang. Design art history. People's fine arts publishing house,.2004. In Chinese

[7] Wenjin Yang. The guide of sustainable development economics. China Environmental Science Press.2005. In Chinese

[8] Zhifeng Liu, Guangfu Liu. Green design [M]. Beijing. Machinery Industry Press.1999. In Chinese

[9] Jiyao Ling, et al. Art design fifteen. Peking University press.2006. In Chinese

[10]Xinhua. What is sustainable development. http://news.xinhuanet.com/misc/2002-08/21/content _533048.htm2006-6-1. In Chinese

[11] He Li, Yueheng Li. Focus on the green design of the ecological environment. Decoration. 2003 fifth. In Chinese 